\title{
School Manager System based on a Personal Information Architecture
}

\author{
Elena Fabiola Ruiz Ledesma ${ }^{1}$, Elizabeth Moreno Galván², Juan Jesús Gutiérrez García ${ }^{3}$, Chadwick Carreto Arellano ${ }^{4}$ \\ Ciencias Básicas Department ${ }^{1}$ \\ Instituto Politécnico Nacional. Escuela Superior de Cómputo and UPIICSA, Mexico, City 1,3,4 \\ Instituto Politécnico Nacional, Cecyt 9, UPIITA, Mexico, City ${ }^{2}$
}

\begin{abstract}
The current technological revolution has provided multiple benefits to human activities. For their part, organizations have had the need to make changes to their business requirements, which have led them to migrate to systems and services in more complex models. Educational institutions have experienced the impact of technological progress, because, regarding school management, information handling requires to be performed through automated processes that also protect data from any human or cyber-attack. The purpose of the paper herein is to show the development and integration of a system dedicated to manage personal information within a school environment, through the implementation of an information management architecture, whose main purpose is to create certified documents that can be shared with other information systems in the same trust environment. Research is descriptive in nature as it pretends to detect abnormalities in the characteristics of PIMS, describe their associations, and prove or reject the hypothesis in order to be compared to subsequent studies.
\end{abstract}

Keywords-Architecture; mobile computing; ubiquitous computing; information management system

\section{INTRODUCTION}

Nowadays, data management represents an important part of information systems. It is important to consider that the value of information provision and handling does not only lie in corporate information, but also in every level where any kind of data is manipulated, whether sensible or publicly held. Therefore, currently, there are several software solutions available in the market that digitally manage information, so it can be used by different applications and systems, such as banks, social network, and databases, which have, in every case, some level of data protection and confidentiality. However, the development of systems that provide the possibility to share information, among them, in a transparent, controlled, and safe way is subject to study.

In this article, a system developed under an architecture that allows managing personal data from mobile system users is presented; such architecture considers several aspects focused on users being able to identify themselves, manage and validate their background, as well as to share and safely arrange such information, thus improving its mobility and ubiquity.

The paper is organized into four sections. The following section provides the related work on the subject matter that acts as the basis for the proposed framework. Section III explains briefly the materials and methods used for the data analysis and elaborates on the framework. Finally, Section IV concludes the paper with a summary of the main findings and future works.

\section{THEORETICAL FRAMEWORK}

\section{A. Related Work}

There are several studies which have proved that there is interrelation between the length of time that has passed since the users previously accessed the data and perception of the difficulty of re-finding information [1]-[5].

The Personal Information Management Systems (PIMS) as organizations have the need to implement software systems to improve their information management, currently, the Personal Information Management Systems (PIMS) [1], [2], comprise an important part of any organizational system. The comparison of some current personal information systems [1][5], is shown in Table I.

\section{B. Research Problem}

Software systems, from all current businesses and institutions, have, at least, one module dedicated to and focused on the information of one group of individuals. As systems for personal information management have not been confidentially and interoperably yet, the research problem lies in the development of systems capable of managing personal information that meet current needs of information storage, manipulation, distribution, and provision in a mobile environment, thus providing precision, coherence, safety, and ubiquity qualities.

\section{Hypothesis}

It is required to follow the information management architecture as a guide for the development of an information system that ensures safe personal information exchange with other heterogeneous systems in the same trust environment.

\section{Rationale}

In virtue of the increase in the development of personal information systems, the decision of developing a school management system applying an architectural scheme that might be referenced as one of the starting points for every organization at the time of being integrated to the digital technology world and adapting the advantages it can provide, especially regarding personal information management if it is seized with due responsibility, has been made. 
TABLE. I. CHARACTERISTICS OF INFORMATION MANAGEMENT SYSTEMS1

\begin{tabular}{|c|c|c|c|c|c|c|c|}
\hline PIMS & $\begin{array}{l}\text { Inf. } \\
\text { verification } \\
\text { and } \\
\text { validation }\end{array}$ & $\begin{array}{l}\text { Information } \\
\text { distribution } \\
\text { channels }\end{array}$ & $\begin{array}{l}24 / 7 \\
\text { information } \\
\text { availability }\end{array}$ & Safety & $\begin{array}{l}\text { Interoperability } \\
\text { with other } \\
\text { systems }\end{array}$ & $\begin{array}{l}\text { Mobile } \\
\text { computing }\end{array}$ & $\begin{array}{l}\text { Ubiquitous } \\
\text { computing }\end{array}$ \\
\hline Business (web) & $\mathrm{X}$ & $X$ & $X$ & $X$ & $X$ & $X$ & \\
\hline $\begin{array}{l}\text { Multimedia content } \\
\text { (photo and video } \\
\text { album) }\end{array}$ & & $X$ & & & $\mathrm{X}$ & $\mathrm{X}$ & $X$ \\
\hline $\begin{array}{l}\text { Tailor-made staff } \\
\text { administrative } \\
\text { management(incidence } \\
\text { control, payroll) }\end{array}$ & $\mathrm{X}$ & & & $\mathrm{X}$ & & & \\
\hline $\begin{array}{l}\text { Entertainment (coail } \\
\text { media) }\end{array}$ & & $X$ & X & & $\mathrm{X}$ & X & \\
\hline
\end{tabular}

\section{E. Definition of Architecture}

Moreno [6], mention that "the architectural design, whose core component is information regarding the personal background of an individual, describes such background as a unique and unrepeatable unit or object immersed in a series of computing elements that permit its creation, bearing, sharing, and management". The structure of such object is presented in Fig. 1.

\section{F. Architectural Model}

Architecture has a series of layers that interact with those adjacent to them, thus allowing that the usefulness of a layer does not interfere with the usefulness of another. The way in which products generated in one layer are useful for the usefulness of an adjacent layer is shown in Fig. 2.

In order to exemplify that the architecture will be able to adapt itself to interoperability policies, according to applicable legislation of the geographical area where it is implemented, for current Mexican provisions, as pointed out in [7], the following guidelines shall be observed:

- Certificates.

- Based on RFC5280 with X509 V3 structure, considering that, for electronic invoicing, FIEL certificates are based on such standard.

○ A length of 2048.

- SHA2-256 cryptographic algorithm.

- Code generation based on asymmetric cryptography.

- Private code (file.key).

○ Public code (file.crt).

- Electronic information maintenance.

In order to extend the validity of electronic documents and/or affirm their existence from a specific date, NOM-151SCFI-2002, or simply NOM-151, specifies the technical elements to achieve such purpose, based on electronic time stamps.

\section{G. School Management System}

In order to show the benefits provided by the development of systems through the application of an architecture that organizes personal data of users, in mobile devices, a School Management Systems that showcases the implementation of personal information management architecture for its development has been developed.

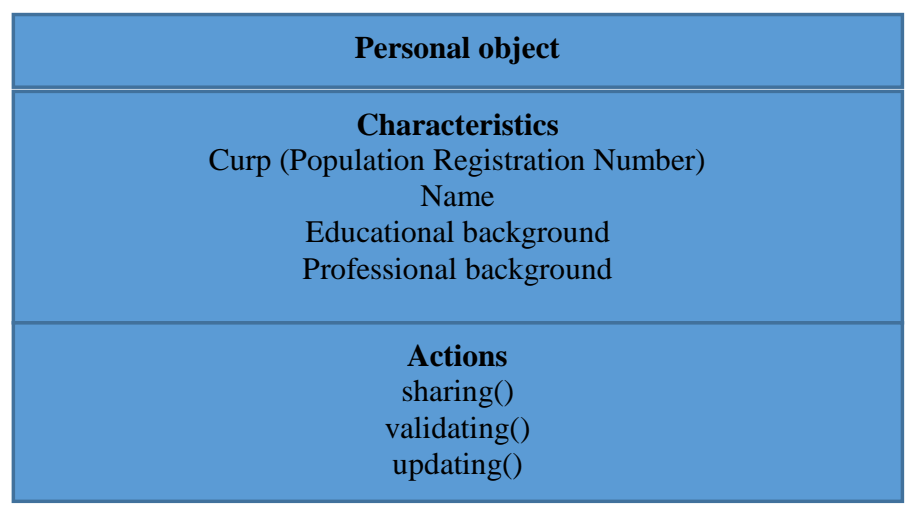

Fig. 1. Personal Object.

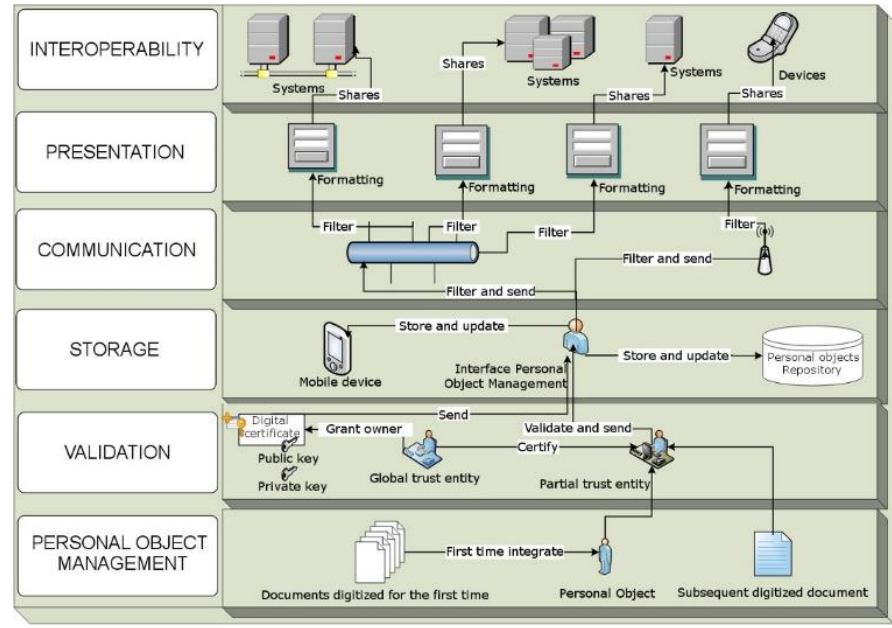

Fig. 2. Collaboration Model among Layers that Comprise the Architecture. 


\section{H. Project's basic Concepts}

The computer system is in charge of automating several administrative and academic processes inside an educational institution, which are necessary for its management and operation. The system facilitates the approach, communication, and interaction among several elements in an educational institution (parents, students, teachers, administrative staff, and coordinators), thus allowing them to interact through it from any place, at any time, and at the most convenient moment.

Regarding safety and interoperability, the system considers information authentication and exchange through digital certificates, as well as digital signing and encryption schemes, besides XML document exporting.

\section{MATERIAL AND METHOD}

Every software system has to be developed by following a methodology (cascade, spiral, XP agile, and SCRUM agile). For the case study here in, a RUP (abbreviation of Rational Unified Process) [8], methodology has been implemented, given the business nature and the need to implement the design architecture, which is robust and requires to be implemented in the appropriate stages.

\section{A. Overview of the System Modules Development Starting Stage}

- Project's definition and scope

The computer system is in charge of automating several administrative and academic processes through the implementation of a web site whose work will consist on solving problems in an academic environment, as well as managing personal data belonging to students and teachers, thus providing more comfort and safety to end users.

The system's scope is determined by the following tasks:

1) To facilitate the interaction among coordinators, teachers, students, and administrative staff.

2) To provide information availability regarding administrative and academic processes, so it is updated in real time.

3) To create a complete and agile form of performing daily activities in the institution, such as evaluating a group of students.

4) Online and in real time availability of the system's tools for those who require using them in the institution.

5) Registration processes of:

- Personal data and documents of students and teachers in adherence with strict follow-up of the privacy and confidentiality notice.

- Enrolments, subjects, groups, and teachers.

\section{B. Creation Stage}

- Artifacts

RUP methodology, in each stage, performs a series of artifacts that support a better comprehension of the study object and the tools needed to achieve both the system's analysis and design (among others). Next, a description of the most representative artifacts is included:

- Definition of the requirements for the project's analysis.

- Management of personal data from students, teachers, and school management administrative staff.

○ Subject management.

○ Schedule management.

○ Attendance management.

- Automation of students' enrollment and reenrollment process.

- Report card, certificates, and completion certificates printing.

○ Enrolled students' list creation.

o Regarding standards $\operatorname{ISO}(2017)[9]$, in order to evaluate software quality, the following shall be considered:

- Usefulness. Uploading students in the school control system shall be made via web.

○ The systems shall cover more than $80 \%$ of the required usefulness, so it complies with every implicit and explicit need. It shall have a high degree of safety, which helps it ensure a god performance and operation of such system.

- Reliability. The system shall be able of keeping its provision level under previously established conditions.

- Usability. It shall be easy to use, user-intuitive, and that requires basic hardware and software knowledge so it can be used without problems.

- Efficiency. The system shall always be ready to perform when a request is made; generating a response will not take too much time.

- Ease of maintenance. When the system presents tolerable failures or unexpected defects, automating changes and system tests shall be easy to do.

- Portability. The system does not require installing any extra tool, apart from default tools. It shall be multifunctional, i.e. it shall be executed from any device where it is needed to access the network.

- Hardware and Software requirements

○ Dedicated server.

○ Operational system: Windows or Linux centOS.

○ Openssl Win 32 or Linux.

○ Mysq1 5.5 o higher, PHP 5 or higher.

- Hard drive space: $20 \mathrm{~GB}$ available.

- Modeling for the project's design. 


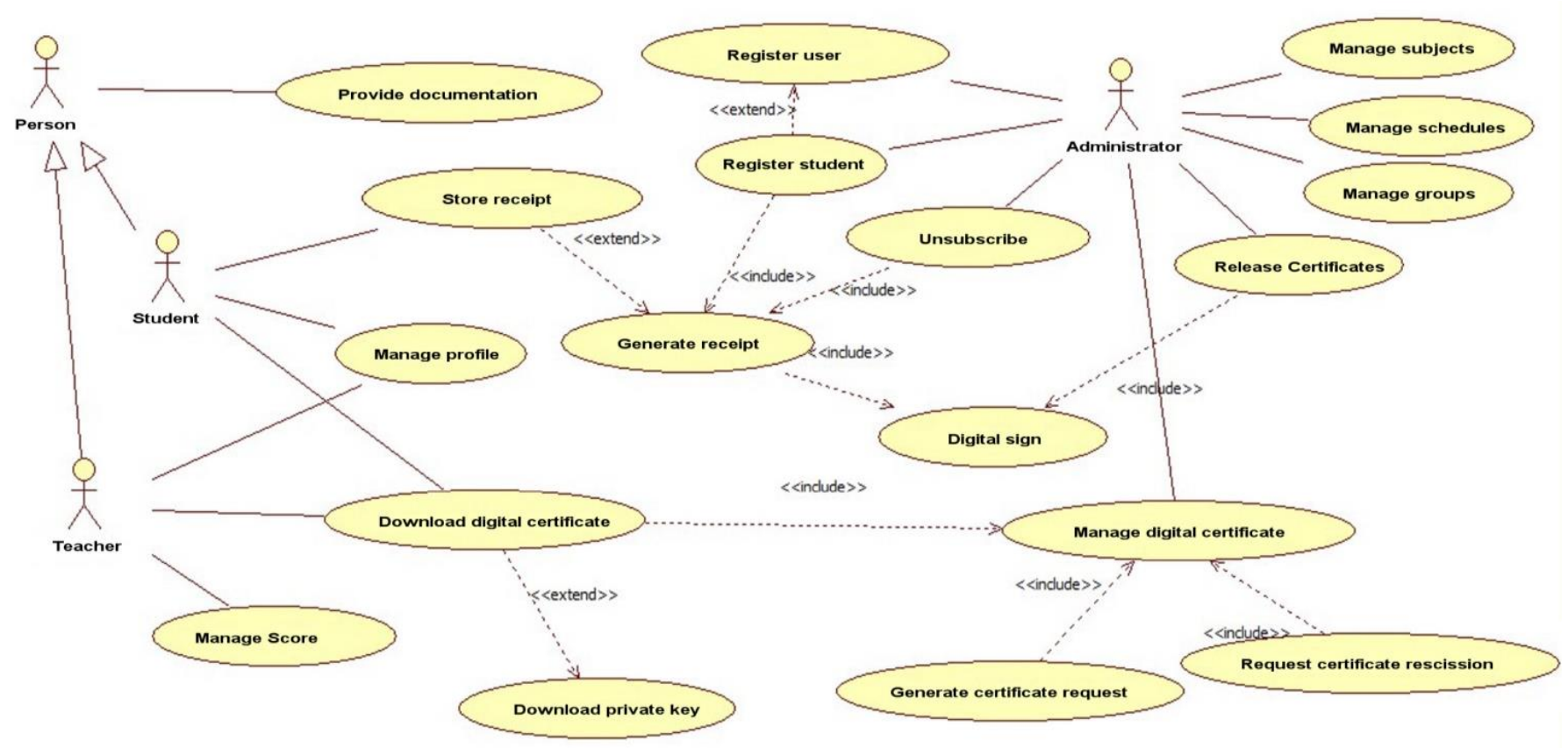

Fig. 3. High Level Case of use Diagram for the System.

RUP uses UML diagrams as system analysis and design tools. The case of use diagram shown in Fig. 3 constitutes a support model to obtain a global view of the system, showcasing actors, functions, and scope.

\section{Construction Stage}

Once the system's analysis and design have been performed, it is possible to make decisions about implementation [10]. The elements that comprise the problem's solution are presented in Fig. 4.

\section{Transition Stage}

This stage comprises the system's implementation process, as well as functionality tests. The products per component represented in the display diagram are presented below.

- Registration entity (web application).

- The entity in charge of receiving and verifying a person's data and documents might have an interface, where the person's necessary data is collected to create its personal object.

- Once the person's data has been collected, the Registration Unit might request the Global Certifying Authority (AC) the issuance of a digital certificate and private code, through an interface like the one shown in Fig. 5, where all the system's users that still do not have a certificate are listed; once this is selected, a .csr file is created and it awaits for an answer from the AC.

\section{E. Global Certifying Authority (AC)}

- The AC shall have its own interface to perform activities related to digital certificates and private codes' issuance, withdrawal, and management. In the web site, there is an interface, where the $\mathrm{AC}$ manager can consult every csr certificate issuance requests made by registration entities within the trust environment, as well as issue such certificate.

When the csr request is signed, a digital certificate and private code is created for the client; those are placed in the server's folder tree, which is created for such purpose; such files are available for the Biased Entity.

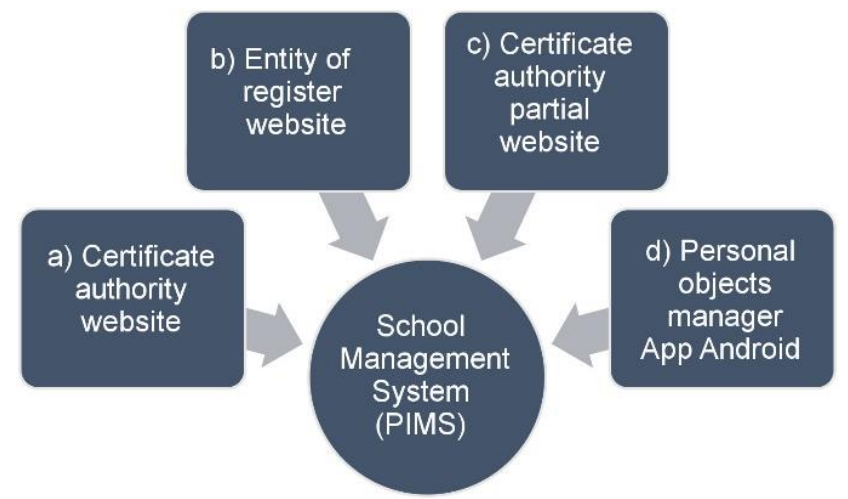

Fig. 4. System Components.

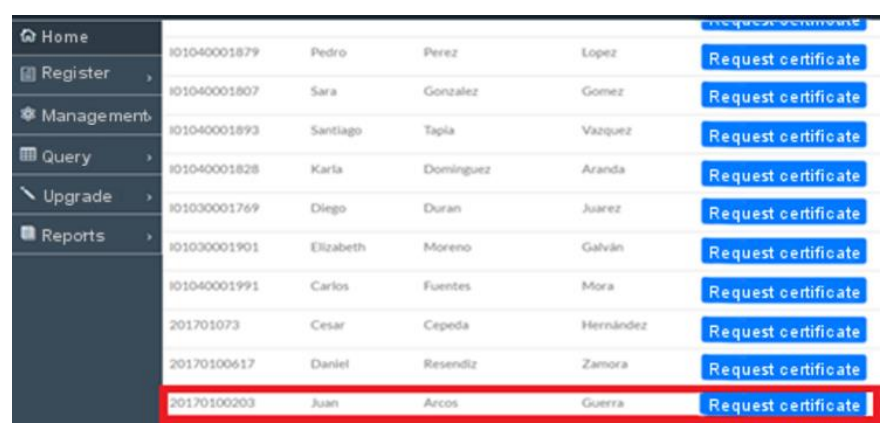

Fig. 5. Screen of the Certificate Issuance Request for a Student. 
- Biased Entity (certificate and code management web site).

- Both the AC and the Biased Certifying Entity have access to the certificate repository; therefore, when $\mathrm{AC}$ has signed a certificate request, the process status is updated, thus allowing the system manager to download the created certificate and private code.

- Biased Certifying Entity (web site).

- The Biased Certifying Entity has the quality of issuing documents that might be signed by such entity, which are accepted by every system from the same trust environment. The enrollment process interface, from which a certificate is created.

\section{F. Maintaining the Integrity of the Specifications}

The template is used to format your paper and style the text. All margins, column widths, line spaces, and text fonts are prescribed; please do not alter them. You may note peculiarities. For example, the head margin in this template measures proportionately more than is customary. This measurement and others are deliberate, using specifications that anticipate your paper as one part of the entire proceedings, and not as an independent document. Please do not revise any of the current designations.

When the data input process is finished, the receipts in PDF and XML formats, which are shown in Fig. 6, are issued. The latter is created under the structure determined by the architecture and it shall include the biased entity signature.

- Mobile application managing the personal object, management of signed documents [11] - [13].

- The objective of the architecture herein is to provide a ubiquity quality to the personal object; to this effect, such object can be carried through a mobile application, whose login and main menu are shown in Fig. 7.

- As aforementioned, a XML document that is required to be annexed to the personal object can be obtained from a server or the device storage external memory. The import process of a XML document to the personal object from the device external memory is presented in Fig. 8.

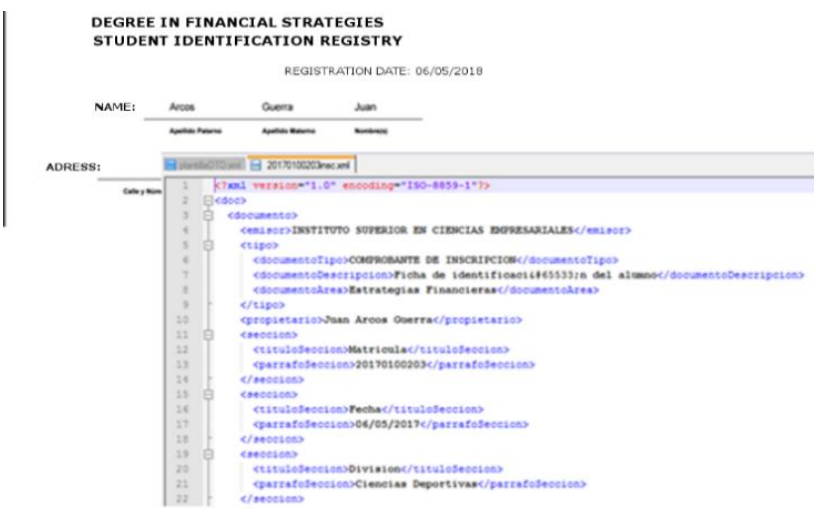

Fig. 6. Fragments of PDF and XML Documents Regarding Enrolment Receipts.
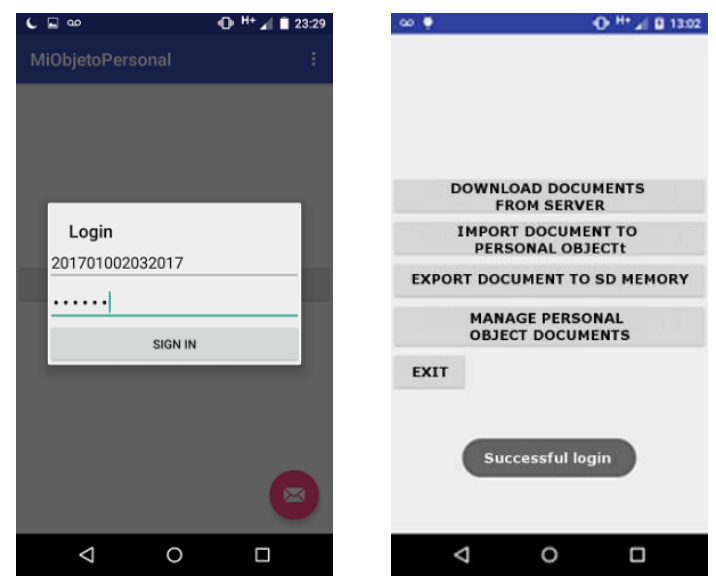

Fig. 7. Mobile Application Login and Main Menu.

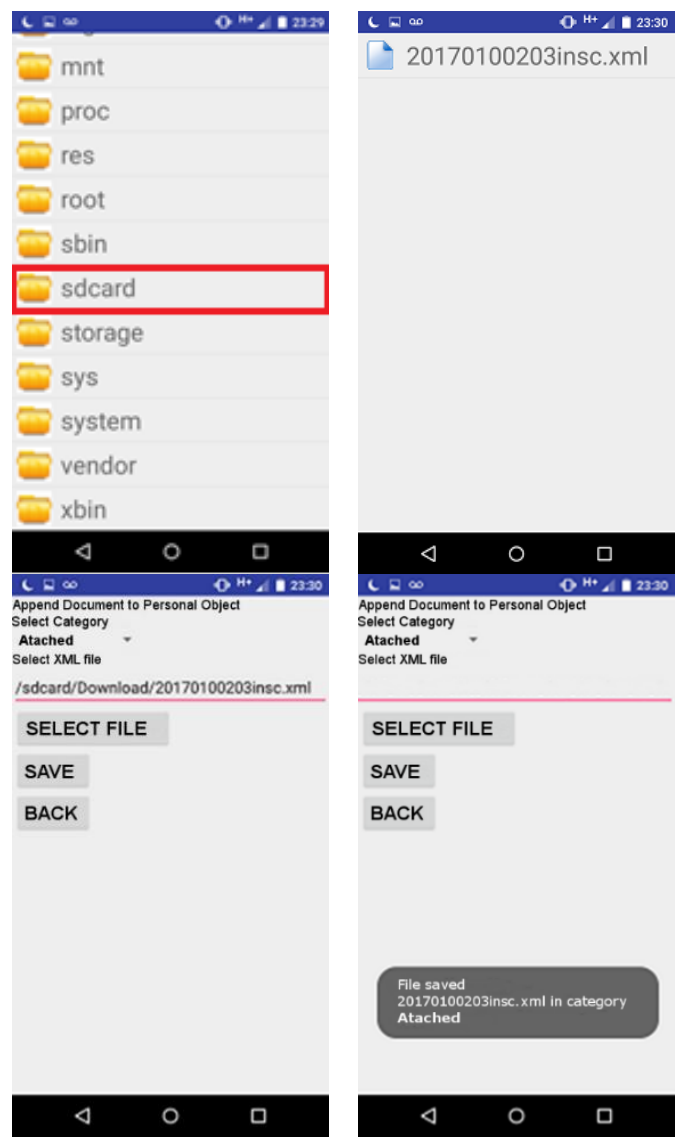

Fig. 8. Document Import to the Personal Object.

- All XML documents stored in the personal object shall have the label structured, established by the architecture, for their appropriate recovery. The process of visualizing a XML document, which is stored in the category Annex of the personal object, is shown in Fig. 9.

- Documents inside the personal object cannot be accessed through any application, as they are stored in the device internal memory. Therefore, in order to share them with other systems, it is necessary to create an external memory export route, where such 
documents can be obtained and such route is accessed through other applications. The screens of the confirmation that a XML document, indicated by the owner (filtering process), has been exported to opExport in the device external memory are presented in Fig. 10.

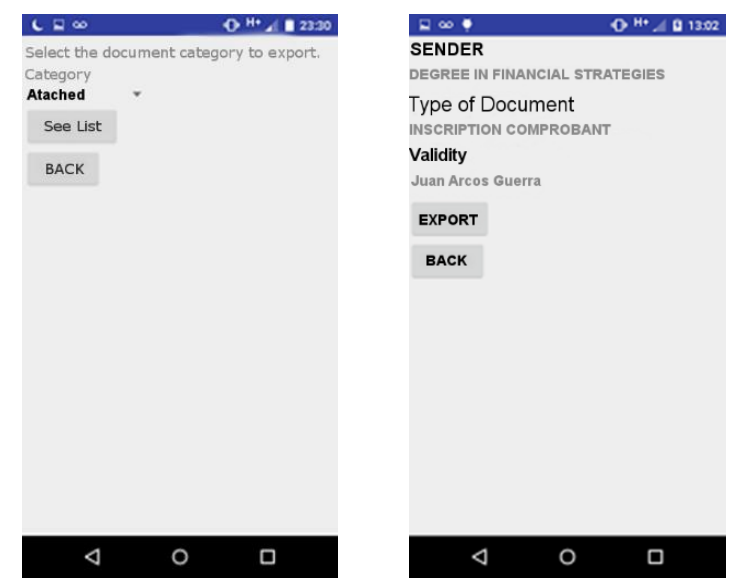

Fig. 9. Visualization of a Personal Object Document.
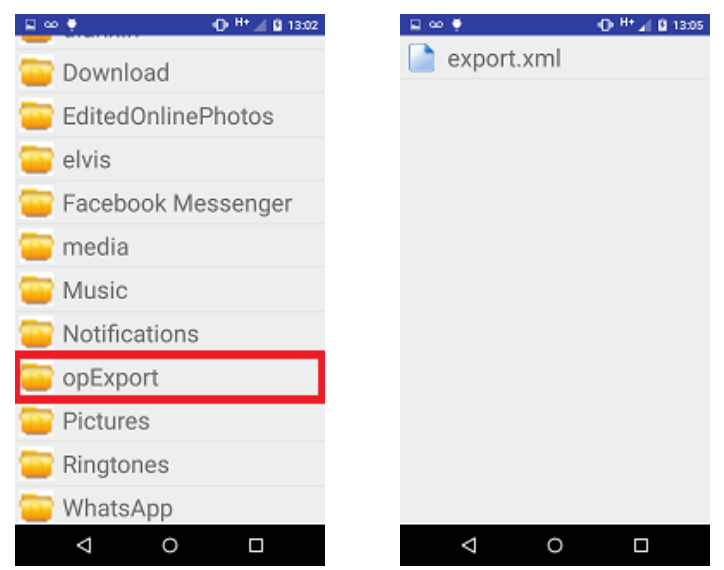

Fig. 10. Document Export from Personal Object to an External System.

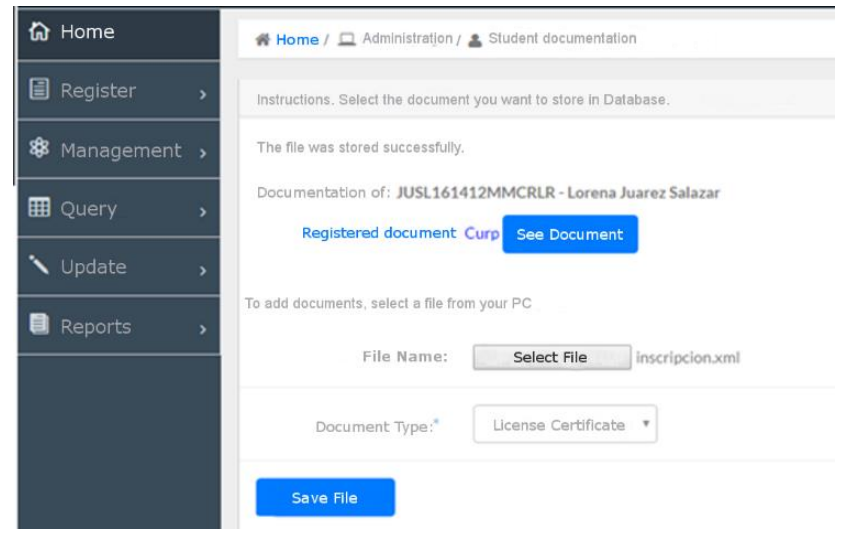

Fig. 11. Systems of Biased Entities that shall Provide an Interface.

\section{G. Document Export from Personal Object to External Memory}

- Biased Certifying Entity, management of signed documents (web site).

- The systems of Biased Entities shall provide an interface (Fig. 11) in order to obtain documents exported by the owner from the personal object.

The reading of a document created under the structure defined by the architecture might be recovered in plain text or by applying a style sheet to facilitate visualization.

\section{RESULTS AND DISCUSSION}

Research, and data collection and analysis are basic procedures to achieve effectiveness of the efforts presented herein, justifying resource allocation and mobilization or the development of more advanced studies on this matter.

\section{A. Methodological Analysis}

The applied research procedure is the technique of observational survey that implies data collection and creation of social interest, through the interrogation of members of the society, using the survey as a tool.

\section{B. Results}

When performing ANOVA statistical analyses to data obtained through survey application, they indicate that users of existing PIMS are not completely satisfied with the quality of information exchange among such PIMS. The results overview, where a filled square represents total satisfaction with quality, an empty triangle represents dissatisfaction with quality, and no graphic represents any quality available for the PIMS are presented in Table II.

According to the following analysis, the opinion about the school management system shows a high degree of acceptance in the evaluated population, whose analysis overview is shown in Table III, where a filled square represents total satisfaction with quality, an empty triangle represents dissatisfaction with quality.

Results show that, currently, several trust gaps previously existing in electronic means to communicate, share information, and make operations such as online shopping have been overcome. Users are opened to new and innovating solutions that facilitate everyday activities and, on the other hand, developers have made great efforts to provide the same level of importance to the creation of intuitive interfaces and business processes.

According to the following analysis, the opinion about the school management system shows a high degree of acceptance in the evaluated population, whose analysis overview is shown in Table III, where a filled square represents total satisfaction with quality, an empty triangle represents dissatisfaction with quality. 
TABLE. II. RESULTS OF SURVEY APPLIED TO PIMS USERS

\begin{tabular}{|c|c|c|c|c|c|c|}
\hline CUALITY & $\begin{array}{l}\text { a) System's } \\
\text { ease of use } \\
\text { (intuitive } \\
\text { GUI) }\end{array}$ & $\begin{array}{l}\text { b) Execution terminal or } \\
\text { device configuration, } \\
\text { required for the system's } \\
\text { operation) (token) ease of } \\
\text { use }\end{array}$ & $\begin{array}{l}\text { c) Personal information } \\
\text { management reliability (It } \\
\text { provides safety services } \\
\text { and mechanisms) }\end{array}$ & $\begin{array}{l}\text { d) } \\
\text { Information } \\
\text { management } \\
\text { ease of use }\end{array}$ & $\begin{array}{l}\text { e) Management's ease of } \\
\text { use of digital certificates } \\
\text { and codes transport and } \\
\text { distribution mechanisms }\end{array}$ & $\begin{array}{l}\text { f) Information } \\
\text { exchange, } \\
\text { generated by the } \\
\text { system with others } \\
\text { ease of use }\end{array}$ \\
\hline $\begin{array}{l}\text { Electronic } \\
\text { invoicing }\end{array}$ & E & & घ & $\square$ & घ & $\Delta$ \\
\hline $\begin{array}{l}\text { Online } \\
\text { banking }\end{array}$ & घ & घ & घ & 口 & 口 & $\Delta$ \\
\hline $\begin{array}{l}\text { Electronic } \\
\text { receipts }\end{array}$ & घ & & घ & & & $\Delta$ \\
\hline $\begin{array}{l}\text { Digital } \\
\text { documents }\end{array}$ & घ & & घ & & & $\Delta$ \\
\hline
\end{tabular}

TABLE. III. Results OF THE SURVEy APPLIED to the USERS OF CASE STUdy PIMSONT Sizes FOR PAPERS

\begin{tabular}{|l|l|l|l|l|}
\hline QUALITY & $\begin{array}{l}\text { a) Use feasibility by } \\
\text { users out of the } \\
\text { information technology } \\
\text { industry. }\end{array}$ & $\begin{array}{l}\text { b) Feasibility of adding } \\
\text { safety components, } \\
\text { proposed by the } \\
\text { architecture for systems, } \\
\text { development }\end{array}$ & $\begin{array}{l}\text { c) XML document } \\
\text { management feasibility to } \\
\text { create any type of document } \\
\text { for systems' development. }\end{array}$ & $\begin{array}{l}\text { d) Document exchange assurance in } \\
\text { heterogeneous systems by XML } \\
\text { document creation under the scheme } \\
\text { established by the architecture. }\end{array}$ \\
\hline $\begin{array}{l}\text { Architecture } \\
\text { implementation in PIMS }\end{array}$ & $\mathbf{n}$ & $\mathbf{v}$ & $\mathbf{v}$ \\
\hline
\end{tabular}

V. CONCLUSIONS

Results show that, currently, several trust gaps previously existing in electronic means to communicate, share information, and make operations such as online shopping have been overcome. Users are opened to new and innovating solutions that facilitate everyday activities and, on the other hand, developers have made great efforts to provide the same level of importance to the creation of intuitive interfaces and business processes.

Data obtained through surveys allowed confirming the general hypothesis and justifying why the design of an architecture that facilitates interoperability among systems is important, while the case study contributed to show that there are no obstacles, regarding technologies and computing tools, to implement the architecture, where the most restrictive identified factor is the organizational approach.

\section{ACKNOWLEDGMENT}

We would like to thank SIP-IPN, COFAA and EDD for to support provided in the development of the research.

\section{REFERENCES}

[1] M. Rustom, A. Nasar, M. Mohd, and M. Ali, M. A "Conceptual Framework for an Interactive Personal Information Management System". International Conference on User Science and Engineering (iUSEr), 2011a, pp. 100-105,

[2] M. Rustom, A. Nasar, M. Mohd, and M. Ali, M. "Personal Information Management Systems and Interfaces: An Overview". International
Conference on Semantic Technology and Information Retrieval, 2011b, pp.197-202, 28-29, Putrajaya, Malaysia.

[3] D. Elsweiler, M. Baillie, and I. Ruthven, "What makes re-finding information difficult? A study of email re-finding," Advances in Information Retrieval, 2011, pp. 568-579.

[4] Tyebjee, K. Charting a Mobility RoadmapVol. 33 Issue 9, p42-43, 2p. Publisher: Cyber Media India Ltd.

[5] W. D. Srisamran. "The development of personal information system: A case study in the faculty of industrial education and technology". 2nd International Conference on Computer Technology and Development (ICCTD 2010), pp. 410-414. King mongkut's university of technology thonburi.

[6] S. Moreno. "Estudio de Arquitecturas de Software para servicios de Internet de las Cosas", thesis. Esc. Téc. Superior de Ingenieros de Telecomunicación, Universidad Politécnica de Madrid, 2015.

[7] A. Rodríguez. Publicación en internet y tecnología XML,. España: RAMA, 2004, pp. 44-123.

[8] G. Booch, J. Rumbaugh, and I. Jacobson.. El proceso unificado de desarrollo de software. USA: Pearson Addison Wesley, 2000.

[9] Sitio official International Organization for Standarization [ISO]. (2017) ISO 2017, [Online] Avaible: http://www.iso.org/iso/home.html.

[10] R. Guzmán. "Arquitectura de Servicios Web Semánticos Sensible al Contexto para Dispositivos Móviles". M. Eng. thesis. CINVESTAV, febrero 2012.

[11] Medina, V. T. (2012). Análisis de la utilización de la Computación Móvil en diferentes procesos y actividades empresariales. Medellin: Universidad EAFIT.

[12] R.Evernden, and E Evernden. Third-generation information architecture. Communications of the ACM, 46(3) 95-98, 2003.

[13] P. Scifleet, S. Williams. "Constructing Digital Documents: Emerging Themes in Documentary Practice", Proceedings of the 44th Hawaii International Conference on System Sciences, 2011. 